\title{
DESFAZENDO MITOS: O QUE ESTÃO FAZENDO COM O SINAES?
}

\author{
Amir LimanA*
}

\begin{abstract}
*Doutor em "Sistemas Sociais e Análise de Políticas Públicas" pela Universidade de Roma "La Sapienza", foi Coordenador Geral do ENADE, junto ao INEP/MEC, desde sua implantação, em 2004 a fevereiro de 2008 e atualmente é Diretor de Desenvolvimento Institucional do CESUMAR - Centro Universitário de Maringá/PRÉ. E-mail: alimana@.uol.com.br
\end{abstract}

Resumo: O artigo trata da descontinuidade das políticas públicas brasileiras e critica as desconstruções que o SINAES vem sofrendo ultimamente, devido aos usos de índices e as práticas de rankings.

Palavras-chave: Políticas públicas. Avaliação da educação superior. SINAES. Rankings.

DECONSTRUCTING MYTHS: WHAT IS BEING DONE TO SINAES?

\begin{abstract}
The paper discusses the descontinuity of Brazilian public policies and criticizes the recent deconstruction of SINAES due to the use of indexes and rankings.
\end{abstract}

Key words: Public policies. Evaluation of higher education. SINAES. Rankings.

Que o atual governo esteja fazendo um enorme esforço para melhorar os nossos índices educacionais ninguém duvida. As ações governamentais nesta área têm contemplado todos os níveis educacionais, desde a pré-escola ao stricto sensu.

Para comprovar a veracidade desta afirmação basta observarmos a contínua ampliação dos recursos públicos destinados à educação, seja com os recursos do FUNDEB (Fundo de Manutenção e Desenvolvimento da Educação Básica e de Valorização dos Profissionais da Educação), ou com programas como o REUNI (Programa de Apoio a Planos de Reestruturação e Expansão das Universidades Federais). Programas como o PROUNI (Programa Universidade para Todos), ou o Brasil Profissionalizado, entre tantos outros, são destinados à inclusão de jovens, seja no ensino superior, seja na formação para o trabalho.

Sabemos que a melhora dos índices educacionais dependem da persistência nos investimentos públicos na educação e que tais índices melhoram incrementalmente no médio e no longo prazo. Isto significa dizer que as políticas educacionais não se prestam às aventuras eleitoreiras, já que quem investe na 
educação, hoje, não colherá, necessariamente, votos amanhã como costumam ser as ações típicas de processos clientelistas e eleitoreiros.

A lentidão com que a melhoria da educação tem evoluído em nosso país está a denunciar, no mínimo, a pouca atenção que este tema tem despertado historicamente nas nossas elites políticas. Ou ainda, denuncia a descontinuidade na execução das políticas públicas de educação. Não é por outra razão que mais de dez por cento de brasileiros ainda são analfabetos (ou 14,1 milhões de pessoas, como revelado pela Pnad) ou, que apenas em torno de doze por cento dos nossos jovens, em idade universitária (dos 18 aos 24 anos), estejam na universidade.

Com a preocupação centrada no tema da educação, o Brasil produziu teóricos de incontestável densidade e espírito público republicano. Pensadores como Anísio Teixeira, Darcy Ribeiro e Paulo Freire, entre tantos outros, ocupam lugar de destaque neste campo. Mesmo assim, disputamos os últimos lugares entre os países no mundo no quesito educação.

Não restam dúvidas de que a descontinuidade nas políticas públicas é uma das marcas históricas do nosso país. Não por outra razão, teóricos da política nacional como Fábio Wanderley Reis, Guilherme O'Donell entre outros, têm se referido a este fenômeno das políticas públicas em nosso país como o "dilema da descontinuidade".

Se, por razões as mais esdrúxulas imagináveis, alguém quisesse buscar um modo seguro e eficiente de desperdiçar os escassos recursos do Estado, certamente encontraria na descontinuidade das políticas o jeito de fazê-lo.

Múltiplas são as hipóteses levantadas para justificar esta "cultura" perversa deste verdadeiro dilema de descontinuidade.

Quiçá a nossa estrutura estatal de um federalismo em que a União se sobressai impetuosamente sobre os outros entes federativos e com um sistema presidencialista (imperial como identificado por alguns teóricos) em que o poder executivo se sobrepõe frente aos poderes judiciário e legislativo, sejam as principais razões deste perdulário hábito de iniciar e abandonar políticas, em completo desprezo com os cidadãos que financiam o Estado.

Ou, então, seria um vício de origem do "fazer política" no Brasil onde, independentemente do matiz ideológico do governo de plantão, a nossa classe política detentora dos cargos de governo, padeceria de uma incapacidade inexorável de resistir à tentação de, a cada política implementada, tentar extrair dividendos para uma "poupança" eleitoreira.

O fato é que das prefeituras aos palácios dos governos estaduais, chegando ao Planalto, em maior ou menor grau, nós convivemos com o nefasto hábito 
de reinventar programas desconsiderando, olimpicamente, tudo aquilo que foi feito pelos antecessores.

Ou pior que isto, muitas vezes em um mesmo governo, ao mudar o ocupante de uma secretaria de um governo municipal, estadual ou um ministro no plano nacional, o novo agraciado com o cargo ignora o que vinha sendo feito por quem o antecedeu. E este hábito se repete internamente em todas as instâncias de poder, das secretarias às diretorias e coordenações, em uma lógica perversa que tem como conseqüência certa o desperdício dos, sempre, escassos recursos públicos.

É à luz desta desanimadora realidade nacional que devemos tentar entender as políticas públicas de nosso país. Mesmo que se, aparentemente, uma política esteja demonstrando a sua eficiência e eficácia, nada garante que a mesma terá continuidade após o primeiro ato da natural "dança das cadeiras" a que o aparato público nacional está exposto em nosso presidencialismo com sistema partidário fragmentado.

É natural no sistema presidencialista, o presidente, o governador ou o prefeito vitorioso do processo eleitoral levar consigo, para compor os primeiros escalões, uma equipe de confiança que terá a tarefa de implementar o seu programa de governo.

Até aqui nada de errado. Porém, vencer um processo eleitoral em um sistema partidário fragmentado e com um sistema eleitoral, como é o nosso (que não garante ao vencedor das eleições do poder executivo a maioria das cadeiras no poder legislativo), obriga o prefeito, o governador ou presidente da República a "tecerem" complexas e pragmáticas negociações no intuito de construírem uma base aliada que garanta a sustentabilidade dos seus governos.

São justamente estas negociações para a composição de maioria nos parlamentos que induzem os executivos a partilharem os espaços de poder no governo que, em geral, levam seus mandatários a gastarem uma boa parte de seus tempos a orquestrar a "dança das cadeiras" nas várias instâncias de poder, originando daí uma boa parte das razões da descontinuidade nas políticas públicas a que nos referíamos anteriormente.

Estas são situações que, se não propriamente republicanas, são compreensíveis dentro da racionalidade instrumental que move a política brasileira. Pior, no entanto, são aquelas mudanças entre os colaboradores dos escalões inferiores do governo, movidas por interesses (nada públicos) de acomodações de compadres, bajuladores ou parentes, ou então, movidos por sentimentos pouco nobres da inveja e perseguição frente a um subalterno. 
Paradoxalmente, nestes últimos casos as substituições nos escalões inferiores são provocadas pelo sucesso alcançado na execução das políticas. Estas são sempre as substituições mais nefastas para a sociedade, já que dispensam os quadros mais capacitados entre os que compõem o governo!

Se tomarmos uma das mais exitosas políticas públicas de educação no governo Lula, que foi a política de avaliação da educação superior, executada por meio de um complexo e profundo Sistema Nacional de Avaliação da Educação Superior, denominado SINAES, desenvolvido no âmbito do Ministério da Educação, veremos que tampouco aí estivemos imunes a este flagelo nacional da descontinuidade da política.

Se não descontinuidade, no sentido de interrupção completa da política, ao menos descaracterização absoluta daquilo que havia sido pactuado pelo governo com a sociedade e o poder legislativo e implementado desde o início do governo Lula com a publicação da denominada Lei do SINAES (Lei 10.861/ 14/09/2004), ainda em vigor, mas profundamente alterada (inconstitucionalmente ao nosso ver) por portarias ministeriais - a exemplo da Portaria Normativa $\mathrm{n}^{\mathrm{o}}$. 4, de 5 de Agosto de 2008.

A invenção de índices - que de tão complexos exigem "notas técnicas" do Ministério da Educação - que em nada se aproxima dos princípios originais do SINAES, só serve para dar um verniz de cientificidade a um imbroglio que, em absoluto, nada significa em termos de avaliação da educação superior, a não ser o de confundir a sociedade brasileira com falsos rankings de excelência de instituições de ensino superior e de frustrar as expectativas da comunidade acadêmica com uma nova cultura avaliativa que aos poucos ia sendo formada.

É angustiante demais para qualquer cidadão que tenha a consciência do quanto foi investido em escassos recursos públicos; em tempo e sonhos dos mais renomados intelectuais brasileiros (e estrangeiros) expertos em avaliação; em infinitas reuniões com a comunidade acadêmica nacional nos quatro cantos do país, num difícil processo de diálogo e convencimento; em dezenas de capacitações de especialistas em avaliação, mobilizando milhares de intelectuais a um custo considerável ao erário público para, ao final (e de forma abrupta), desconsiderar olimpicamente os preceitos do SINAES que se consolidou como alternativa ao tão criticado provão, justamente por relativizar, nos processos avaliativos de cursos e instituições, a importância do desempenho do estudante.

É decepcionante constatar que, tão somente para rankear as instituições de ensino superior do nosso país, o sistema anterior, que o SINAES veio a substituir, era mais simples e eficiente. Poderíamos, sem muita criatividade, ter alterado o nome do antigo programa e, em vez de "provão", poderíamos 
chamar o "novo" sistema de "enadão" e tudo estaria resolvido de modo muito mais simples, sem qualquer arrojo acadêmico.

Vemos aqui, mais uma vez, a descontinuidade de uma política pública virtuosa. As conseqüências são sempre as mesmas: desperdício de recursos públicos escassos, já que para rankear instituições o antigo Provão era muito eficiente; frustração das expectativas da comunidade acadêmica envolvida nas instituições de ensino superior, e isto é possível deduzir das inúmeras manifestações dos principais intelectuais e pesquisadores da avaliação em todos os eventos dedicados ao tema; perda de um tempo precioso de todos os que se envolveram no processo avaliativo entre tantas conseqüências danosas que sempre se fazem sentir quando da descontinuidade da política.

Em termos de eficiência e eficácia da política pública de avaliação da educação superior, observada a partir da implantação do Sistema Nacional de Avaliação da Educação Superior - SINAES, ninguém questiona os grandes avanços a que se chegou. Por que então se decidiu mudar, na sua essência, o SINAES com a introdução de conceitos estranhos à sua própria filosofia? As respostas oficiosas dizem que a autarquia responsável pelo processo avaliativo não teria condições de efetuar todas as avaliações nos milhares de cursos e instituições distribuídos no território nacional.

Mas, se as avaliações são feitas por especialistas das áreas do conhecimento das IES nacionais e as mesmas são pagas pelas próprias instituições avaliadas, bastaria tomar a decisão política de implementar o processo avaliativo como determina a lei do SINAES e capacitar os avaliadores que milhares de avaliações seriam feitas como, de fato, vinham sendo feitas, apenas se intensificaria o processo avaliativo!

De fato aqui foi criado um verdadeiro mito: o mito da impossibilidade de avaliar todos os cursos e instituições do país. Parece-nos, no mínimo, falta de criatividade ou, então, seria uma indisposição para criar as condições para executar a política de avaliação como prevista em lei. Nada disto resiste aos fatos, já que o processo avaliativo vinha ocorrendo sem maiores percalços, a não ser aqueles normais na implementação de uma política pública complexa, transparente e responsável. 